\title{
Knowledge Attitude and Practice on Halitosis Among Dental Students and its Management
}

\author{
Nurul Husniyah binti Che Soh¹, Dhanraj Ganapathy² and Revathi Duraiswamy ${ }^{3}$ \\ ${ }^{1}$ Saveetha Dental College and Hospitals Saveetha Institute of Medical \\ and Technical Sciences Saveetha University Chennai, India \\ ${ }^{2}$ Professor \& Head Department of Prosthodontics Saveetha Dental College and Hospitals \\ Saveetha Institute of Medical and Technical Sciences Saveetha University Chennai, India \\ ${ }^{3}$ Senior Lecturer Department of Prosthodontics Saveetha Dental College and Hospitals \\ Saveetha Institute of Medical and Technical Sciences Saveetha University Chennai, India
}

\section{ABSTRACT}

Halitosis originates from an oral or a non-oral source. It is formed by volatile compounds that are formed due to pathological and non-pathological reasons. Oral malodours is very common in society and it was stated that more than $50 \%$ of the general population have halitosis. Poor oral hygiene, periodontal disease, tongue coat, food impaction, unclean dentures, faulty restorations, oral carcinomas, and throat infections contributed to $90 \%$ of the factors for halitosis. A survey was conducted amongst the undergraduate students in a University hospital. A total of 95 responses were obtained from the students. Results were analysed and compared using the SPSS Statistical Software by doing both the frequency tests and correlation tests. This study showed that $48.42 \%$ of the participants found that halitosis was very common throughout their clinical practices. Based on their knowledge of the main reason for halitosis, $47.37 \%$ of the students agreed that poor oral hygiene was the main factor. $42.11 \%$ participants were aware that volatile compounds contribute to halitosis. In regard to their clinical practice, $42.11 \%$ of their methods of preventing halitosis are by practising good oral hygiene. Overall, $86.32 \%$ of the participants agreed that more knowledge about halitosis and its effective management is necessary in the future.

KEY WORDS: HALITOSIS, GINGIVITIS, PERIODONTITIS, ORAL MALODOUR, VOLATILE MOLECULES.

\section{INTRODUCTION}

Halitosis or oral malodours is used to define any disagreeable bad or unpleasant odour originating from the mouth air and breathing. Halitosis comes from a latin word raised from halitus which is breathed air and the osis that is the pathologic alteration (Hine, 1957). Other terms

\section{ARTICLE INFORMATION}

*Corresponding Author: dhanraj@saveetha.com

Received 15th June 2020 Accepted after revision 10th August 2020 Print ISSN: 0974-6455 Online ISSN: 2321-4007 CODEN: BBRCBA

Thomson Reuters ISI Web of Science Clarivate Analytics USA and Crossref Indexed Journal

\section{Clarivate
Analytics}

NAAS Journal Score 2020 (4.31) SJIF: 2020 (7.728)

A Society of Science and Nature Publication,

Bhopal India 2020. All rights reserved.

Online Contents Available at: http//www.bbrc.in/

Doi: http://dx.doi.org/10.21786/bbrc/13.7/83 which are commonly used to define and characterize the halitosis are foetor oris, oral malodour, mouth odour, bad breath and bad mouth odour (Sanz, Roldán and Herrera, 2001) (Cortelli, Barbosa and Westphal, 2008) (Bogdasarian, 1986). Halitosis is an undesirable condition that becomes a common complaint among both genders and in all index age groups. It not only causes social and psychological drawbacks but also may influence an individual's relation with surrounding people (Tonzetich, 1977).

Halitosis is a common problem in society and approximately more than 50\% of the general population is experiencing halitosis (Nachnani, 2011). Halitosis is produced by volatile molecules that may be due to pathological and non-pathological contributors, originating from 
an oral or a non-oral source. Sulfur compounds, aromatic compounds, nitrogen-containing compounds, amines, short-chain fatty acids, alcohols or phenyl compounds, aliphatic compounds, and ketones are those volatile compounds responsible for oral malodour (Goldberg et al., 1994) (Loesche and Kazor, 2002) (Amano et al., 2002). Furthermore, there are some bacteria that are responsible for halitosis as they produce hydrogen sulfide and methyl mercaptan from serum. The bacteria includes Fusobacterium nucleatum, Fusobacterium periodonticum, Prevotella intermedia, Prevotella loescheii, Treponema denticola and etc (Persson et al., 1990).

90\% cases of halitosis originated from oral cavity. The temperature of the oral cavity reaches up to $37 \mathrm{C}$ and may be changing between 34 and $37 \mathrm{C}$ while humidity may reach up to $96 \%$ in oral exhalations(Nodelman, Ben-Jebria and Ultman, 1998)(Nodelman, Ben-Jebria and Ultman, 1998; Zehentbauer, Krick and Reineccius, 2000). These conditions favour a suitable environment for bacterial growth. Over 500 bacterial species (Miyazaki et al., 1995) found in the oral cavity are able to produce odorous compounds that induce halitosis. Poor oral hygiene plays an important role in these conditions as it multiplies halitosis causative bacteria and worsen oral malodour. They are Gr-negative species and proteolytic obligate anaerobes (Tyrrell et al., 2003)(Morita and Wang, 2001) and commonly retained in tongue coating and periodontal pockets (Tonzetich, 1977). Halitosis may be induced in healthy individuals that have no history of halitosis and periodontal disease due to retention of bacteria on the tongue surface (Wåler, 1997). These bacteria produce odorous compounds when degrading organic substrates such as glucose, mucins, peptides, and proteins present in saliva, crevicular fluid, oral soft tissues, and retained debris (Tonzetich, 1977) (McNamara, Alexander and Lee, 1972)(Persson, Claesson and Carlsson, 1989).

Accumulation of food debris and dental bacterial plaque on the teeth and tongue in poor oral hygiene individuals can cause caries and periodontal diseases like gingivitis and periodontitis that lead to oral malodor ('Oral Complications of Cancer and its Management', 2010) (Takeuchi et al., 2010)). In addition, halitosis may occur in untreated deep carious lesions that form a retention area for food debris and dental bacterial plaque. Flow of saliva may influence the human breath. In reduced salivary flow or xerostomia, the intensity of sulfur compounds is increased. Saliva involves buffering or cleaning and maintaining the bacteria at an optimum level in the oral cavity (Nachnani, 1997). Decrease of salivary flow may impact negative effects on selfcleaning of the mouth and inadequate cleaning of the mouth lead to halitosis (Debaty and Rompen, 2002). Medications such as antidepressants, antipsychotics, diuretic, and antihypertensive reduce salivary flow in addition to salivary gland diseases (e.g., diabetes, Sjorgen's syndrome), chemotherapy, or radiotherapy
(Kleinberg, Wolff and Codipilly, 2002)(Koshimune et al., 2003).

About $8 \%$ of the halitosis cases originate from an extraoral source and the incidence is rarely seen. Causes of this type of halitosis include respiratory system problems, gastrointestinal disease, hepatic disease, hematological or endocrine system disorders and metabolic conditions (Aylıkcı and Colak, 2013). Besides, halitosis may occur in individuals consuming garlic, onions, and spiced foods. Same effect may happen in patients administering drugs such as alcohol, tobacco, betel, solvent abuse, chloral hydrate, nitrites and nitrates, dimethyl sulfoxide, disulphiram, somecytotoxics, phenothiazines, amphetamines, suplatast tosilate, and paraldehyde (Ciçek et al., 2003)(Lu, 1982).

Previously our department has published extensive research on various aspects of prosthetic dentistry ('Evaluation of Corrosive Behavior of Four Nickelchromium Alloys in Artificial Saliva by Cyclic Polarization Test: An in vitro Study', 2017; Ganapathy, Kannan and Venugopalan, 2017; Jain, 2017a, 2017b; Ranganathan, Ganapathy and Jain, 2017; Ariga et al., 2018; Gupta, Ariga and Deogade, 2018; Anbu et al., 2019; Ashok and Ganapathy, 2019; Duraisamy et al., 2019; Varghese, Ramesh and Veeraiyan, 2019), this vast research experience has inspired us to research about various methods practiced and general knowledge of halitosis among dental students. The main purpose of this study being that by determining the frequently practiced methods in management of halitosis, a better insight on the degree of understanding and its effects on the patient's satisfaction can be obtained.

\section{MATERIAL AND METHODS}

Study Setting: This cross-sectional study was done among undergraduate students (includes third years, final years, interns) of Saveetha Dental College and Hospitals. A total of 95 students participated in this study. Study Subjects A total of 95 students participated in this study of which $33.68 \%$ (32) were third years, $13.68 \%$ (13) were final years and the remaining 52.63\% (50) were interns.

Methodology: A survey was conducted through an online standard questionnaire with 10 multiple choice questions sent via a Google Form application. The questionnaire consisted of questions about the knowledge, awareness and practices regarding halitosis in patients experienced by these students throughout clinical practices. Adequate time was provided to fill the questionnaire. The responses of the students were recorded, analysed, checked for completeness and were taken up for assessment.

Statistical Analysis: After data was collected and coded, the statistical analysis was done using IBM SPSS Statistical Software package (Version 23.0). All the frequency tests were carried out and the Chi-square test was done at a significance level. 


\section{RESULTS AND DISCUSSION}

A total of 99 students participated in the study, 33.68\% (32) were third years, 13.68\% (13) were final years and the remaining 52.63\% (50) were interns as shown in Graph 1. Assessment on their personal experience of the occurrence of patients with halitosis gave the following results, $46(48.42 \%)$ agreed that it was very common, $39(41.05 \%)$ have admitted that it was rare and only $10(10.53 \%)$ has never encountered such an experience as displayed in Graph 2. When inquired about the main reason of halitosis in those patients, 45 $(47.37 \%)$ accepted that it was due to poor oral hygiene, $30(31.58 \%)$ believed it was because of food impaction, $13(13.68 \%)$ agreed it was periodontal disease, 4 (4.21\%) said it was tongue coating and $3(3.16 \%)$ chose other reasons as the main factor contributing halitosis (Graph 3). In Graph 4, analysis of their awareness on halitosis mainly due to volatile compounds gave the following results, 55 (57.89\%) did not aware at all and 40(42.11\%) had awareness on this.

Figure 1: Pie chart showing responses to the question among undergraduates based on their year of study. $52.63 \%$ of the respondents were interns. $13.68 \%$ of the respondents were final year undergraduate students. $33.68 \%$ of the respondents were third years.

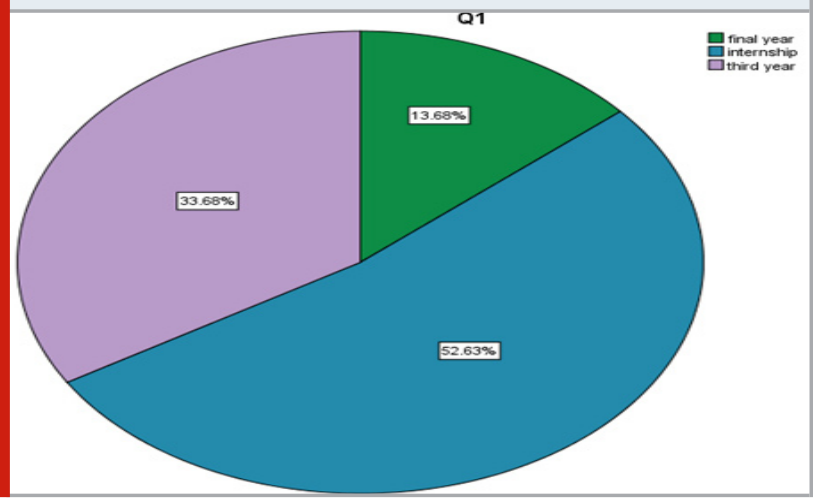

Graph 2: Pie chart showing responses to the question, "Based on your experience, have you encountered patients with halitosis?". 48.42\% of the respondents commonly encountered halitosis among dental patients. $41.05 \%$ of the respondents stated that the halitosis is rare and $10.53 \%$ of the respondents never encountered halitosis during clinical procedures.

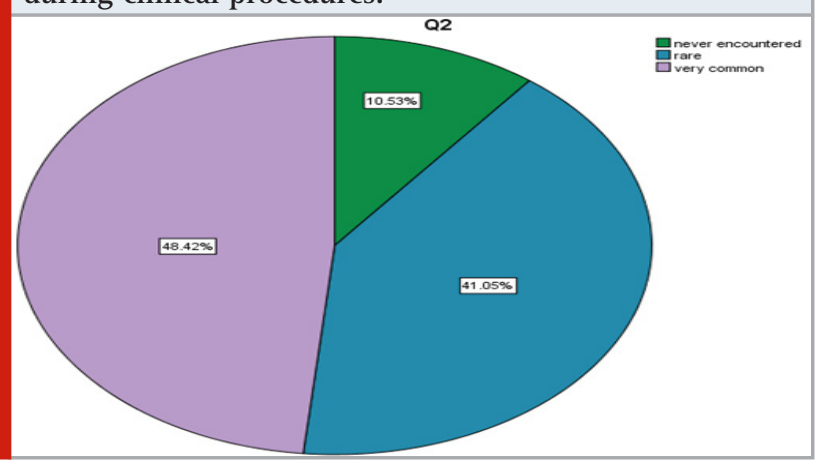

Graph 3: Pie chart showing responses to the question "What do you think is the main reason for halitosis?". $31.58 \%$ of the respondents stated that the halitosis is due to food impaction, $13.68 \%$ because of periodontal disease, $47.37 \%$ poor oral hygiene and $4.21 \%$ due to tongue coating.

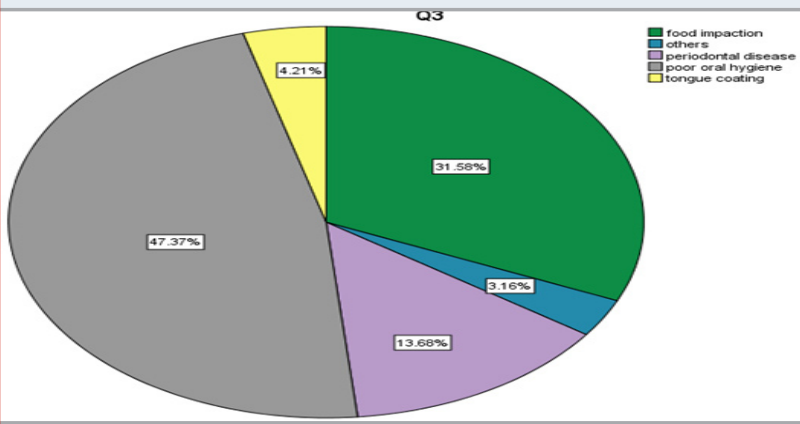

Graph 4: Pie chart showing responses to the question "Do you aware that halitosis is mainly due to volatile compounds?". 57.89\% of the respondents had awareness of the reason while $42.11 \%$ of the respondents were not aware.

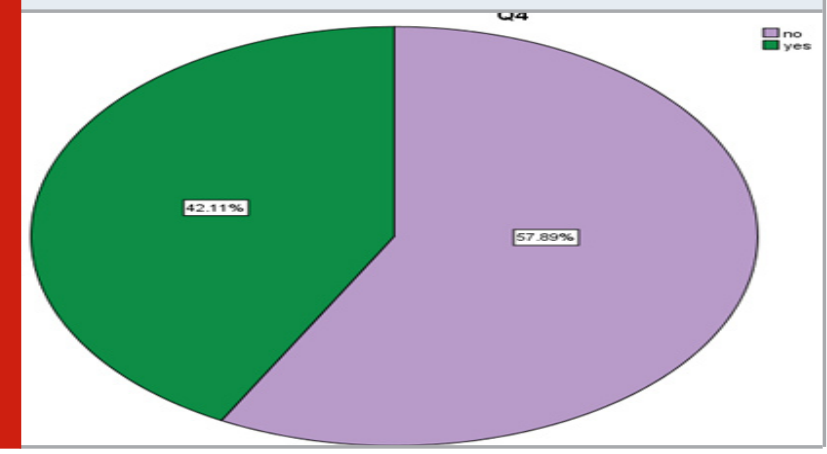

Graph 5: Pie chart showing responses to the question "Do you aware that factors of halitosis can be oral and non-oral causes?". 58.95\% of the respondents were aware while $41.05 \%$ of the respondents had no awareness of the factors.

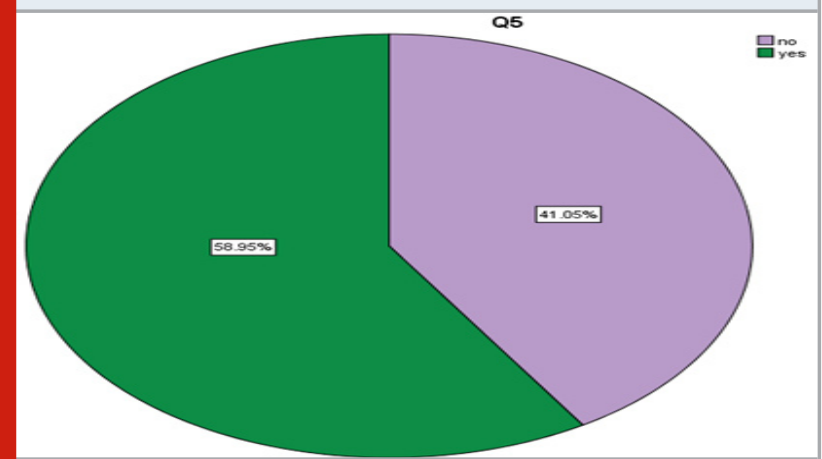

Based on graph 5, 56 (58.95\%) respondents agreed that factors of halitosis can be oral and non-oral causes while $39(41.05 \%)$ had no knowledge on this. 54 (56.84\%) respondents did not know aware that Gr negative species and proteolytic obligate anaerobes that mainly 
retained in tongue coating and periodontal pockets can cause halitosis and about $41(43.16 \%)$ were aware halitosis occurred because of these bacteria (Graph 6). As presented in Graph 7, 60 (63.16\%) of the respondents were not aware while 35 (38.64\%) of the respondents had awareness that gingival inflammation may lead to halitosis.

Graph 6: Pie chart showing responses to the question "Do you aware that Gr negative species and proteolytic obligate anaerobes mainly retained in tongue coating and periodontal pockets can cause halitosis?". 56.84\% of the respondents were aware while $43.16 \%$ of the respondents had no awareness these bacteria can cause halitosis.

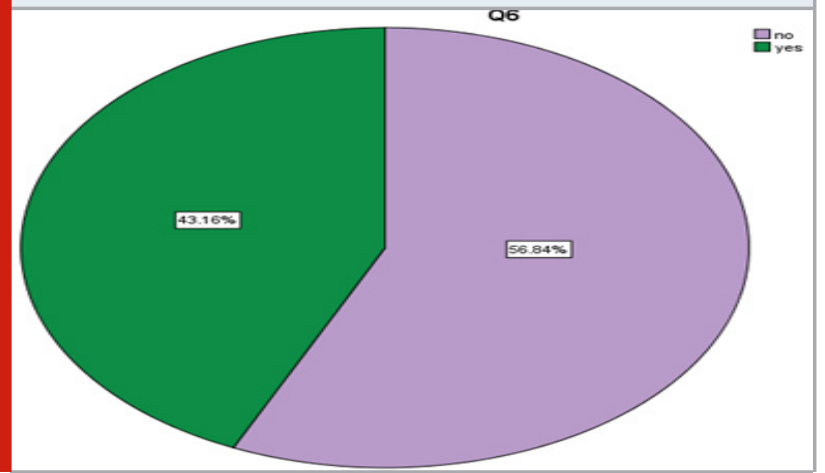

Graph 7: Pie chart showing responses to the question "Do you aware that inflammation of gingival and periodontal tissues causes oral malodor?". 63.16\% of the respondents were aware while $38.64 \%$ of the respondents had no awareness that gingival inflammation may lead to halitosis.

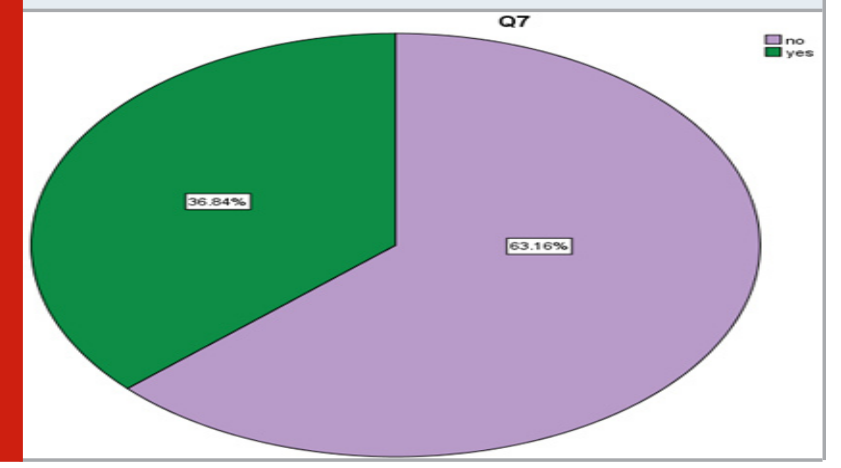

As shown in Graph 8, 71(74.74\%) of the respondents were aware while $19(25.26 \%)$ of the respondents had no awareness of the possibility of untreated deep carious lesions that create the retention area for food debris and dental bacterial plaque can cause oral malodour. Based on graph 9, 62 (65.26\%) of the respondents believed that reduced salivary flow may influence bad odour as it affects the cleaning of the mouth while 33 (34.74\%) did not know that reduced salivary flow can cause halitosis. In graph 10, 91 (95.79\%) agreed that dietary habits such as intake of garlic, onions, spiced foods cause unpleasant odours. On the other hand, only 4 (4.21\%) did not aware that types of dietary products will affect the patients' mouth odour. Graph 11 shows 40 (42.11\%) agreed good oral hygiene can terminate oral malodour, 28 (29.74\%) chose antiseptic mouthwash as a solution to get rid halitosis, 22 (23.16\%) believed scaling and root planning can reduce the bad odour while 3 (3.16\%) agreed with tongue cleaning and only 2 (2.11\%) suggested renewal of old restorations as a method of reducing or eliminating foetor oris.

Graph 8: Pie chart showing responses to the question "Do you aware that halitosis may be due to untreated deep carious lesions that create the retention area for food debris and dental bacterial plaque?". 74.74\% of the respondents were aware while $25.26 \%$ of the respondents had no awareness.

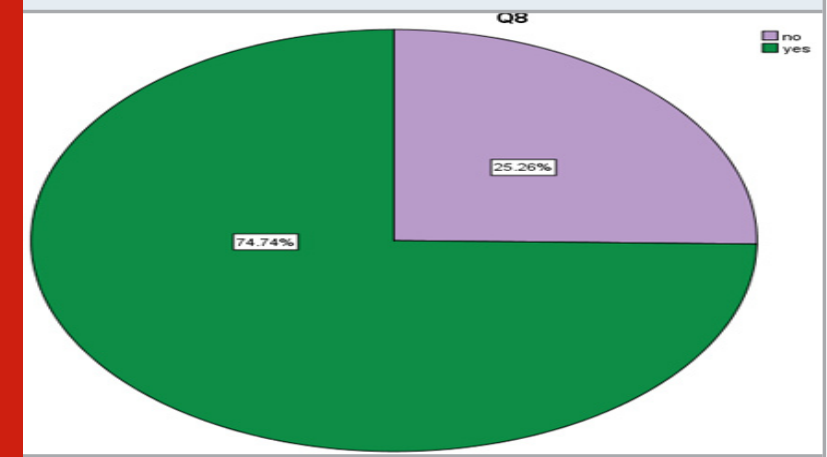

Graph 9: Pie chart showing responses to the question "Do you aware that halitosis occurs when there is salivary flow reduction that affects inadequate cleaning of the mouth?". $65.26 \%$ of the respondents were aware while $34.74 \%$ of the respondents did not know that reduced salivary flow causes halitosis.

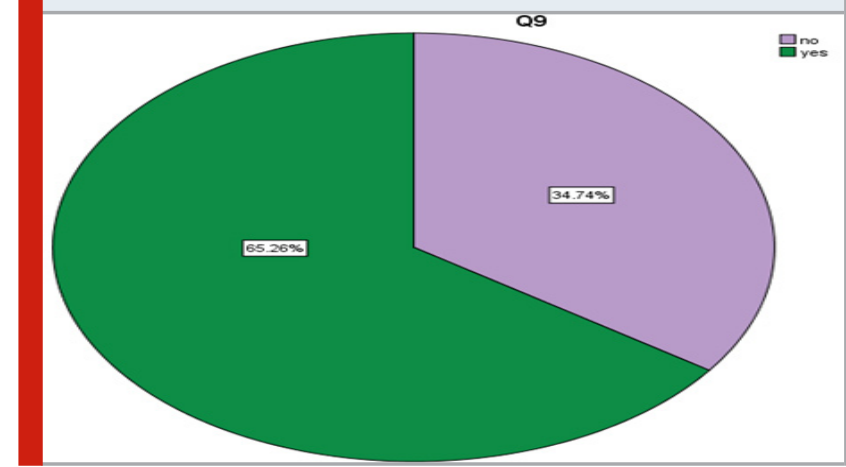

This cross-sectional study was used to assess the knowledge, awareness and practices in halitosis and its management among students of Saveetha Dental College. Majority of the participants have admitted that halitosis was a very common occurrence during their clinical practice. This finding is not a rare finding as nearly more than $50 \%$ of the general population have halitosis as reported by Nachani et al. (Nachnani, 2011). Most of the respondents in the current study are aware that retention $\mathrm{Gr}$ negative species and proteolytic obligate anaerobes on tongue lead to oral malodour. Nachani et al. recognized that oral malodor is caused mainly by facultative bacteria on the tongue that produce volatile organic compounds (Nachnani, 2011). Based on this 
study, majority agreed that most causes of halitosis originated from the oral cavity. This is supported by the research done by Scully et al. and Kasap et al. in which $90 \%$ of the patients with halitosis originated from oral cavity while only $9 \%$ of the cases reported due to nonoral reasons. 1\% cases reported the incidence due to diet and drugs (Scully, Porter and Greenman, 1994)(Kasap, Zeybel and Yüceyar, 2009).

Graph 10: Pie chart showing responses to the question "Do you aware that dietary products such as garlic, onions, spiced foods cause unpleasant odours?". 95.79\% of the respondents agreed while $4.21 \%$ of the respondents had no awareness that dietary habits influence breath odour.

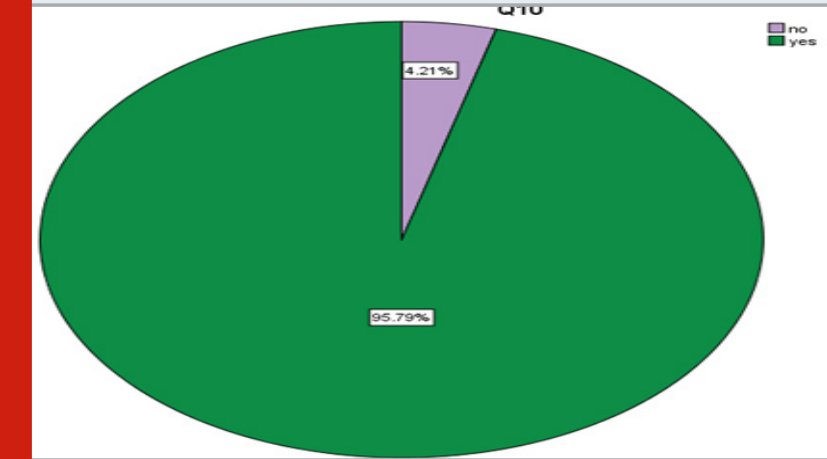

Graph 11: Pie chart showing the responses to the question "In your opinion, what is the best way to reduce or eliminate halitosis?". 29.74\% of the respondents stated that antiseptic mouthwash is the best solution, $42.11 \%$ of the respondents chose good oral hygiene, $23.16 \%$ agreed with scaling and root planing, 2.11\% chose renewal of old restorations and $3.16 \%$ chose tongue cleaning.

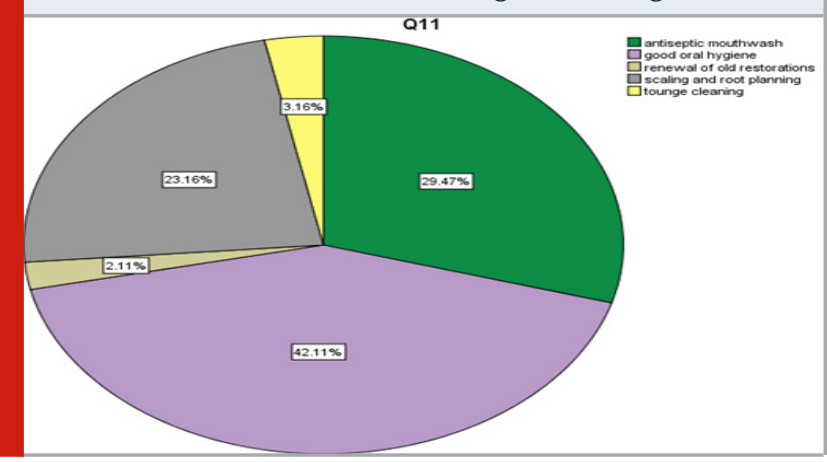

As reported by Davies et al., gingival inflammation and various forms of periodontitis can increase unpleasant breath odor ('Oral Complications of Cancer and its Management', 2010)(31). Reduction in salivary flow is believed to be one of the main reasons of halitosis. This statement was obtained from this study and can be justified by study done by Alamoudi et al. 2004 where he reported that inadequate cleansing of the mouth due to reduction of salivary flow causes halitosis (Alamoudi et al., 2004). Based on Babacan et al. 2011, food or plaque retention areas result in the release of volatile compounds and cause halitosis (Babacan et al., 2011). Present study believed that dietary products such as garlic, onions and spiced food may influence the breath odor. This study is justified by study done by Lu et al 1982 (Lu, 1982). Based on this study, most respondents believed that good oral hygiene plays an important role in preventing oral malodour. Similar to the assessment done by Nachani et al, it highlighted the importance of active practices of using proper oral hygiene products that can decrease the amount of halitosis significantly for an individual (Nachnani, 2011).

Graph 12: Pie chart showing the responses to the question "Is more knowledge on halitosis and its management necessary?". $86.32 \%$ of the respondents confirmed that they need more knowledge of halitosis and its effective prevention. $13.68 \%$ respondents stated that they are well aware about halitosis and its management.

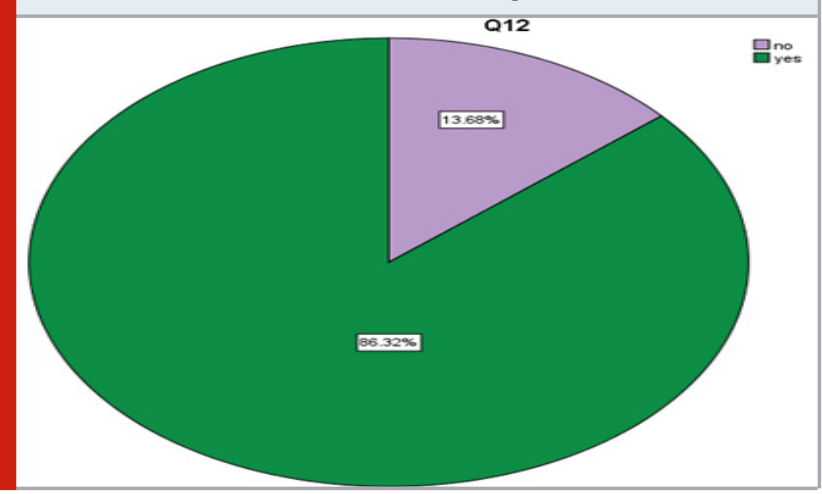

\section{CONCLUSION}

The knowledge and awareness about halitosis and its management among the dental students was moderate. Halitosis can be treated if its etiology can be detected properly. As halitosis gives negative effects on an individual's social life, early preventive management as well as treatment should be implemented at the earliest to avoid distressing effects on people with halitosis and thus improve the quality of life.

\section{ACKNOWLEDGEMENTS}

\section{Nil}

\section{Conflict of Interest: Nil}

\section{REFERENCES}

Alamoudi, N. et al. (2004) 'Salivary characteristics of children and its relation to oral microorganism and lip mucosa dryness', The Journal of clinical pediatric dentistry, 28(3), pp. 239-248.

Amano, A. et al. (2002) 'Monitoring ammonia to assess halitosis', Oral surgery, oral medicine, oral pathology, oral radiology, and endodontics, 94(6), pp. 692-696.

Anbu, R. T. et al. (2019) 'Comparison of the Efficacy of Three Different Bone Regeneration Materials: An Animal Study', European journal of dentistry, 13(1), pp. 22-28.

Ariga, P. et al. (2018) 'Determination of Correlation of 
Width of Maxillary Anterior Teeth using Extraoral and Intraoral Factors in Indian Population: A Systematic Review', World Journal of Dentistry, 9(1), pp. 68-75. Ashok, V. and Ganapathy, D. (2019) 'A geometrical method to classify face forms', Journal of oral biology and craniofacial research, 9(3), pp. 232-235.

Aylıkcı, B. U. and Colak, H. (2013) 'Halitosis: From diagnosis to management', Journal of natural science, biology, and medicine. ncbi.nlm.nih.gov, 4(1), pp. 14-23.

Babacan, H. et al. (2011) 'Effect of fixed appliances on oral malodor', American Journal of Orthodontics and Dentofacial Orthopedics, pp. 351-355. doi: 10.1016/j. ajodo.2009.03.055.

Bogdasarian, R. S. (1986) 'Halitosis', Otolaryngologic clinics of North America, 19(1), pp. 111-117.

Ciçek, Y. et al. (2003) 'Effect of tongue brushing on oral malodor in adolescents', Pediatrics international: official journal of the Japan Pediatric Society, 45(6), pp. 719-723.

Cortelli, J. R., Barbosa, M. D. S. and Westphal, M. A. (2008) 'Halitosis: a review of associated factors and therapeutic approach', Brazilian oral research, 22 Suppl 1, pp. 44-54.

Debaty, B. and Rompen, E. (2002) '[Origin and treatment of bad breath]', Revue medicale de Liege, 57(5), pp. 324-329.

Duraisamy, R. et al. (2019) 'Compatibility of Nonoriginal Abutments With Implants: Evaluation of Microgap at the Implant-Abutment Interface, With Original and Nonoriginal Abutments', Implant dentistry, 28(3), pp. 289-295.

Evaluation of Corrosive Behavior of Four Nickelchromium Alloys in Artificial Saliva by Cyclic Polarization Test:An in vitro Study' (2017) World Journal of Dentistry, 8(6), pp. 477-482.

Ganapathy, D. M., Kannan, A. and Venugopalan, S. (2017) 'Effect of Coated Surfaces influencing Screw Loosening in Implants: A Systematic Review and Meta-analysis', World Journal of Dentistry, 8(6), pp. 496-502.

Goldberg, S. et al. (1994) 'Cadaverine as a putative component of oral malodor', Journal of dental research, 73(6), pp. 1168-1172.

Gupta, P., Ariga, P. and Deogade, S. C. (2018) 'Effect of Monopoly-coating Agent on the Surface Roughness of a Tissue Conditioner Subjected to Cleansing and Disinfection: A Contact Profilometric Study', Contemporary clinical dentistry, 9(Suppl 1), pp. S122S126.

Hine, M. K. (1957) 'Halitosis', The Journal of the American Dental Association, pp. 37-46. doi: 10.14219/ jada.archive.1957.0147.

Jain, A. R. (2017a) 'Clinical and Functional Outcomes of Implant Prostheses in Fibula Free Flaps', World Journal of Dentistry, 8(3), pp. 171-176.

Jain, A. R. (2017b) 'Prevalence of Partial Edentulousness and Treatment needs in Rural Population of South India', World Journal of Dentistry, 8(3), pp. 213-217. Kasap, E., Zeybel, M. and Yüceyar, H. (2009) 'Halitosis (a®lz kokusu)', Güncel Gastroenteroloji, 13(2), pp. 72-76.

Kleinberg, I., Wolff, M. S. and Codipilly, D. M. (2002) 'Role of saliva in oral dryness, oral feel and oral malodour', International dental journal, 52 Suppl 3, pp. 236-240.

Koshimune, S. et al. (2003) 'Low salivary flow and volatile sulfur compounds in mouth air', Oral surgery, oral medicine, oral pathology, oral radiology, and endodontics, 96(1), pp. 38-41.

Loesche, W. J. and Kazor, C. (2002) 'Microbiology and treatment of halitosis', Periodontology 2000, pp. 256-279. doi: 10.1034/j.1600-0757.2002.280111.x.

Lu, D. P. (1982) 'Halitosis: an etiologic classification, a treatment approach, and prevention', Oral surgery, oral medicine, and oral pathology, 54(5), pp. 521-526.

McNamara, T. F., Alexander, J. F. and Lee, M. (1972) 'The role of microorganisms in the production of oral malodor', Oral surgery, oral medicine, and oral pathology, 34(1), pp. 41-48.

Miyazaki, H. et al. (1995) 'Correlation between volatile sulphur compounds and certain oral health measurements in the general population', Journal of periodontology, 66(8), pp. 679-684.

Morita, M. and Wang, H. L. (2001) 'Association between oral malodor and adult periodontitis: a review', Journal of clinical periodontology, 28(9), pp. 813-819.

Nachnani, S. (1997) 'The effects of oral rinses on halitosis', Journal - California Dental Association. europepmc.org, 25(2), pp. 145-150.

Nachnani, S. (2011) 'Oral malodor: causes, assessment, and treatment', The Compendium of continuing education in dentistry, 32(1), pp. 22-4, 26-8, 30-1; quiz 32, 34.

Nodelman, V., Ben-Jebria, A. and Ultman, J. S. (1998) 'Fast-responding thermionic chlorine analyzer for respiratory applications', Review of Scientific Instruments, pp. 3978-3983. doi: 10.1063/1.1149208. Oral Complications of Cancer and its Management' (2010). doi: 10.1093/med/9780199543588.001.0001.

Persson, S. et al. (1990) 'The formation of hydrogen sulfide and methyl mercaptan by oral bacteria', Oral Microbiology and Immunology, pp. 195-201. doi: 10.1111/j.1399-302x.1990.tb00645.x.

Persson, S., Claesson, R. and Carlsson, J. (1989) 'The capacity of subgingival microbiotas to produce volatile sulfur compounds in human serum', Oral microbiology and immunology, 4(3), pp. 169-172.

Ranganathan, H., Ganapathy, D. M. and Jain, A. R. (2017) 'Cervical and Incisal Marginal Discrepancy in Ceramic Laminate Veneering Materials: A SEM Analysis', Contemporary clinical dentistry, 8(2), pp. 272-278.

Sanz, M., Roldán, S. and Herrera, D. (2001) 'Fundamentals 
of breath malodour', The journal of contemporary dental practice, 2(4), pp. 1-17.

Scully, C., Porter, S. and Greenman, J. (1994) 'What to do about halitosis', BMJ . bmj.com, 308(6923), pp. 217-218.

Takeuchi, H. et al. (2010) 'The association of periodontal disease with oral malodour in a Japanese population', Oral Diseases, pp. 702-706. doi: 10.1111/j.16010825.2010.01685.x.

Tonzetich, J. (1977) 'Production and origin of oral malodor: a review of mechanisms and methods of analysis', Journal of periodontology, 48(1), pp. 13-20. Tyrrell, K. L. et al. (2003) 'Anaerobic bacteria cultured from the tongue dorsum of subjects with oral malodor',
Anaerobe, 9(5), pp. 243-246.

Varghese, S. S., Ramesh, A. and Veeraiyan, D. N. (2019) 'Blended Module-Based Teaching in Biostatistics and Research Methodology: A Retrospective Study with Postgraduate Dental Students', Journal of dental education, 83(4), pp. 445-450.

Wåler, S. M. (1997) 'On the transformation of sulfurcontaining amino acids and peptides to volatile sulfur compounds (VSC) in the human mouth', European journal of oral sciences, 105(5 Pt 2), pp. 534-537.

Zehentbauer, G., Krick, T. and Reineccius, G. A. (2000) 'Use of humidified air in optimizing APCI-MS response in breath analysis', Journal of agricultural and food chemistry, 48(11), pp. 5389-5395. 